\title{
Adulteration of honey and available methods for detection - a review
}

\author{
Blanka Zábrodská, Lenka Vorlová \\ University of Veterinary and Pharmaceutical Sciences Brno, Faculty of Veterinary Hygiene and Ecology, \\ Department of Milk Hygiene and Technology, Brno, Czech Republic
}

Received October 2, 2014

Accepted January 14, 2015

\begin{abstract}
Honey adulteration is a topical issue because increasingly sophisticated adulteration methods are constantly being developed and the official (legislative) determination of the quality indicators of honey is unable to detect most methods of honey adulteration. In addition, while the popularity among consumers is constantly growing, the worldwide production of honey is unstable. The aim of this review was to provide a current overview of methods suitable for the detection of individual methods of adulteration.
\end{abstract}

Bee product, NIR, HPLC, isotope analysis

Honey is one of humankind's oldest food products. It contains a number of nutritionally important substances that support good health and recovery. It is a characteristic sugary foodstuff; according to current regulations, apart from other forms of honey no other substances or additives can be added to it (Codex Alimentarius 2011).

Increasing environmental pollution and spread of diseases has led to a decrease in global honeybee populations. This fact coupled with a higher demand means that honey is becoming an increasingly scarce commodity and consequently, honey adulteration is on the rise. Honey adulteration can be direct or indirect. Direct adulteration means that a substance is added directly to honey. Indirect adulteration happens when honeybees are fed adulterating substance. Plants that are sources of substances used for honey adulteration can be classified as $\mathrm{C} 3$ or $\mathrm{C} 4$ plants, based on their carbon metabolism. The $\mathrm{C} 3$ plants fix atmospheric $\mathrm{CO}_{2}$ using the Calvin $(\mathrm{C} 3)$ cycle, and they have a lower ${ }^{13} \mathrm{C} /{ }^{12} \mathrm{C}$ ratio than $\mathrm{C} 4$ plants that fix $\mathrm{CO}_{2}$ using the Hatch-Slack (C4) cycle. Most of the honey-contributing plants like rice, wheat and beet are $\mathrm{C} 3$ plants whereas maize and sugarcane are $\mathrm{C} 4$ plants. In the Czech Republic, adulteration of honey is mainly done using sugars from $\mathrm{C} 3$ plants.

The addition of these syrups is difficult to detect in laboratory assays as the carbohydrate profiles can be artificially made up to closely resemble that of true honey (Mehryar and Esmaiili 2011). Indirect adulteration, or feeding honeybees with such solutions or even crystalline sucrose, has recently become a serious problem.

The consumer is often faced with worthless substitutes but sometimes also with a dangerous cocktail of chemicals such as antibiotics, colourings and hydroxymethyl furfural (HMF). According to the regulatory authorities, nearly half of all honey on the Czech market is tainted in one way or another. The criteria for honey quality have been laid out in the European Council regulation No. 2001/110/ES, Codex Alimentarius (2001) - Standard for Honey and Decree No. 76/2003 Coll. of the Ministry of Agriculture of the Czech Republic.

\section{Indirect adulteration of honey}

Indirect adulteration of honey is accomplished by feeding honeybees with industrial sugars at the stage when broods become naturally available. Such indirect adulteration is extremely difficult to detect. 
Methods of detecting indirect adulteration

Cordella et al. (2005) describe the development of high performance anion exchange chromatography with Pulsed Amperometric Detection (HPAEC-PAD) for the analysis of honey to detect adulteration combined with chemometric techniques for processing chromatograms for better discrimination of pure and adulterated honey. This method was investigated using honey samples containing between $10 \%$ and $40 \%$ of different industrial sugar syrups used for the feeding of honey bees. Honey samples were from French beekepers and the syrup samples from a French supplier (Ickowicz SA). Characterization of untampered and adulterated samples was satisfactorily completed using linear discrimination analysis and canonical analysis (96.5\%). As a control, honeybees were fed with bee-feeding syrups. This practice is particular to bee-keeping, and it was shown that such feeding can affect the sugar composition of the honey produced, if conducted without proper protective measures.

Ruiz-Matute et al. (2010a) studied the sugar composition of high-fructose corn syrup (HFCS) using gas chromatography coupled with mass spectrometry (GC-MS). Sucrose syrups were analysed in parallel as a control. HFCS was shown to contain fructosyl-fructose and other unknown sugars that could be fructosyl-glucose. Honey produced using syrups for bee-feeding and was also analysed to detect the effect of these syrups on sugar composition. Fructosylfructose was detected in honey made by bees fed HFCS. Fructosyl-fructose was detected also in honey from free-flying bees and bees fed sucrose syrups, but at lower levels.

Guler et al. (2014) investigated the sensitivity of methods for the analysis of carbonisotope ratios. They analysed a total of 100 samples of unadulterated honey, honey made by bees fed with different amounts (5, 20 and 100 litres/colony) of sugar syrups. These syrups included corn syrups with high fructose-85 (HFC-85\%), with moderate fructose-55 (HFC-55\%), bee-feeding syrups (BFS), glucose syrups (GMS), and sucrose syrups (SS). The honey samples were analysed for their $\mathrm{D}^{13} \mathrm{C}$ values for honey sugars and proteins, the difference in the $\mathrm{D}^{13} \mathrm{C}$ values of the proteins and sugars $\left(\mathrm{Dd}^{13} \mathrm{C}\right)$ and the percentage of $\mathrm{C} 4$ sugars. Adulteration in honey from colonies fed syrups at 5 litres/colony was not detectable, but it was possible to detect adulteration in colonies fed 20 and 100 litres/colony of HFC-85, and 100 litres/colony of HFC-55. The official methods (AOAC 978. 17 1995; AOAC 991.41 1995; AOAC 998.12 2005) and the internal standards for the detection of carbon isotope ratios are not effective in detecting adulteration of honey made by feeding bees syrups made from C3 plants such as sugarbeet (Beta vulgaris) and wheat (Triticum vulgare).

Bertelli et al. (2010) published an effective method for the detection of honey adulterated using sugar syrups. It involves one-dimensional (1D) and two-dimensional (2D) nuclear magnetic resonance (NMR) coupled with multivariate statistical analyses. They used 63 samples of honey from various botanical sources and seven different sugar syrups marketed as specific bee-keeping products. They analysed 63 unadulterated honey samples and 63 samples of honey from colonies fed with seven different sugar syrups commonly used in adulteration of honey. The best discrimination model involved 1D-spectra and a crossverification analysis showed a prediction capacity for this model of $95.2 \%$. The $2 \mathrm{D}$ NMR analyses also gave satisfactory results (cross-verification showed $90.5 \%$ accuracy).

\section{Direct adulteration of honey}

Direct adulteration is the addition of foreign substances directly to honey.

\section{Methods of detecting direct adulteration}

Traditional analyses of chemical composition and physical properties of honey are commonly used to detect direct adulteration. They are routinely applied in the honey trade 
but these analytical methods are relatively time-consuming and require tedious preparation of the samples as well as complex analytical equipment (Cozzolino et al. 2011). Honey adulteration can also be detected using several modern methods such as measuring stable carbon-isotope ratios, NMR or differential calorimetry. Much attention has been paid to measuring major sugars in honey with gas chromatography (GC) and liquid chromatography coupled to various types of detectors (Abdel-Aal et al. 1993; Bogdanov et al. 2004).

\section{Botanical or geographical origin}

The quality of honey and its specific character are determined by the specific flora and vegetation in the area from which the honey originates and the diversity of the ecosystem in which the bees are kept, specifically in non-industrial areas. The botanical origin of the honey therefore significantly affects its organoleptic properties.

The geographical origin of honey is often associated with low prices as some countries allow year-round honey production. The broods are often huge compared to the ones in the Czech Republic, and the price of labour is low. Despite factoring for long-distance transport, such honey could therefore cost much less than honey produced in the Czech Republic. However, several qualitative indicators of honey from distant lands are considerably different from those of traditional Czech honey. This does not necessarily mean that foreign honey is of lower quality but it carries some risk of being substandard. Hence considerable importance is given to analysing the geographical and botanical origins of honey.

Anklam (1998) discussed the problem of how to determine authenticity including selection of the appropriate analytes for detecting the geographical and botanical origin of honey. The determination of individual indicators such as 5-hydroxymethyl furfural (HMF), moisture, enzyme activity, nitrogen content, mono- and disaccharides, drug and pesticide residues in honey does not give us information regarding the botanical or geographical origin of honey. The botanical origin can be determined by analysing flavonoids, pollen, aromatic compounds, and other specific components. Other substances such as oligosaccharides, amino acids or trace compounds can probably be used to determine the geographical origin. A promising approach to verifying the geographical and botanical origins would be to combine several methods and a large number of detected analytes. It is always necessary, however, to include sensory evaluation of honey.

Castro-Vázquez et al. (2014) analysed the indicators useful for identification of the botanical origin of lavender honey. Honey was verified chemically and sensorically and underwent pollen analysis. Fourteen physico-chemical properties, 26 types of pollen, 13 sensory properties, and 80 volatile substances were identified or quantified. They showed a high concentration of $\gamma$-nonalactone, farnesol and acetovanillone - these were identified for the first time in this work as components of honey aroma. Other compounds including several lactones, dehydrovomifoliol, 4-methoxyacetophenone and decanal have been proposed as chemical markers for lavender honey. The results identified lavender honey as a single-origin honey with respect to its botanical origin, on the basis of the analysis of a sufficient number of substances to enable such identification.

\section{Pollen analysis}

In recent years honey has been subjected to pollen DNA analysis as a result of attempts to falsify its botanical and geographical origins. Only few methods of extracting DNA from honey are available, and they are time-consuming and laborious.

Guertler et al. (2014) developed an automated method of extracting DNA from pollen in honey using the Maxwell 16 and Maxwell 16 FFS instruments. The optimized method included modifications of several parameters. The automated extraction was faster and the DNA purity and yield higher. The results from real-time PCR using DNA extracted by the automated method are comparable to those obtained using manually extracted DNA. No 
inhibition of PCR was detected. The utility of this method was verified on several different common honey samples.

Pollen analysis is one of the oldest and most laborious methods, requiring highly skilled and well-trained laboratory personnel. Puusepp and Koff (2014) describe the results of pollen analysis of Estonian honey samples obtained between 2000 and 2011. A total of 325 samples with a mean of 400 pollen grains each were analysed. The main emphasis was on the floral spectrum of plants and the identification of the most important plant sources for the particular honey. They identified more than 120 pollen types. The results showed that the most common pollen types were Rosaceae, Brassicaceae, Salix, and Trifolium. Pollen from Apiaceae, Fabaceae, Asteraceae, Poaceae, Fagopyrum esculentum, Frangula Alnus, and Calluna were present in more than $25 \%$ of the samples. Typical Estonian honey is multi-origin and the average number of plant sources for one honey is 13 . In the period covered by the study, there was an increase in the percentage of Brassicaceae and Salix pollen grains, whereas Rosaceae and Calluna pollen decreased. The concentration of pollen grains varied from 100 up to 700,000 per gram of honey. This new information brings new insight into the pollen composition of Estonian honey and could contribute to the development of analytical standards for the pollen content of Estonian honey.

Belay et al. (2014) examined samples of forest honey with respect to their botanical origin using pollen and sensory analysis and the quantification of crystallization and colour. A total of 16 samples of honey were collected from two typical localities (Chiri and Wabero). The botanical origin of the samples was examined via qualitative pollen analysis by counting 500 pollen grains using a harmonised method. Granulation, colour, and sensory properties of the honey were determined by visual inspection. The samples were analysed for tetracycline. It is clear from the results that honey from the Wabero locality comes mainly from Syzygium guineense, whereas honey from the Chiri locality was of a multi-flower origin. The honey samples were amber in colour, no tetracycline residues were detected and the formation of granules was slow.

\section{Physico-chemical analysis}

Cimpoiu et al. (2013) examined the physical and biochemical properties of Romanian honey in order to distinguish the plants from which they originate. They evaluated the total content of phenolic compounds, total protein, total free amino acid content, colour intensity (ABS (450)), $\mathrm{pH}$, ash content, and antioxidant activity. They examined 26 commercially available samples of honey from six flower types (acacia, sunflower, forest, mixed, lime and buckthorn). All samples showed significant differences with regard to their properties. The values were within the approved limits in accordance with EU legislation. Total phenolics, total protein, total free amino acid and colour intensity varied considerably. Forest honey had the highest antioxidant activity; the lowest antioxidant activity was found in acacia honey. Acorrelation was observed between the type-origin of honey and its physical and biochemical properties. The study shows that, depending on the botanical origin of honey, there are notable differences in the 1,1-diphenyl-2-picrylhydrazyl (DPPH), and the total phenolics content. The identified indicators can provide enough information for classification and resolution of the botanical origin of honey. Moreover, these characteristics, together with other tests may be used to determine adulteration.

Acquarone et al. (2007) studied 19 different samples of honey of varying origin from different regions of Argentina. They analysed 7 physico-chemical properties (water content, ash, lactones, water activity, total acidity, $\mathrm{pH}$ and electrical conductivity). When the pattern of the electric conductivity and the $\mathrm{pH}$ following dilution were studied, they found that the $\mathrm{pH}$ decreased exponentially with increasing concentration of honey. Dependence of electrical conductivity on the concentration of honey has a maximum value of kappa (кmax) which corresponds to $30-35 \%$ of dry matter in honey. In a given geographical 
area, ash and acidity were useful for determining the botanical origin of honey. The best indicators for discrimination of honey with varying geographical origin were $\mathrm{pH}$ and electrical conductivity as a function of changes in the concentration of honey.

Silvano et al. (2014) studied physico-chemical properties (moisture, hydroxymethyl furfural, colour, electrical conductivity, free fatty acids, glucose, fructose, and sucrose) and sensory characteristics (smell, taste, appearance, and consistency). These indicators were determined in samples of honey from the southeast region of Buenos Aires (Argentina). Analysis of variance showed significant differences between mean values for hydroxymethyl furfural, colour, electrical conductivity, and sucrose content. Cluster analysis and linear discriminant analysis showed that the samples were grouped with respect to the sampling area, which coincided with the results of principal component analysis. These results suggest the possibility of classification of honey by the geographic origin using physico-chemical properties, whereas sensory properties were not useful for determining the geographical origin.

\section{FT-IR, FT-NIR}

Almeida-Muradiana et al. (2014) used Fourier transform infrared attenuated total reflectance spectroscopy (FT-IR ATR) to analyse various honey samples from north-eastern Brazil. The authors used 9 different honey samples ( 6 of a single origin and 3 mixed) obtained from the CEARAPI company. Samples were subjected to FT-IR ATR, palynological and sensory analyses. The results showed that mid-infrared spectrometry can be used as a screening method for routine analysis of Brazilian honey, because it is rapid, nondestructive, and accurate.

Woodcock et al. (2007) investigated the potential of near-infrared spectroscopy (NIR) for determining the geographical origin of honey. Overall, they used 167 unfiltered honey samples (88 Irish, 54 Mexican, and 25 Spanish) and 125 samples of filtered honey (25 Irish, 25 Argentine, 50 Czech, and 25 Hungarian). Spectra were recorded in the transflectance mode. They used various modelling methods such as partial least squares (PLS), regression, and soft independent modelling of class analogs (SIMCA), and also various pre-treatments. For unfiltered honey the SIMCA model was the best, correctly classifying 95.5\%, 94.4\%, and 96\% for Irish, Mexican, and Spanish honey, respectively. The PLS discriminant analysis correctly identified $100 \%$ of each of these classes of honey. In the case of filtered honey, best models were produced using SIMCA; correct classification was obtained in $91.7 \%, 100 \%, 100 \%$, and $96 \%$ for the Argentinian, Czech, Hungarian, and Irish symplex, respectively. The PLS2 discriminant analysis correctly identified $96 \%$, $100 \%, 100 \%$, and $100 \%$ for the Argentinian, Czech, Hungarian, and Irish honey samples, respectively. Overall, the SIMCA and PLS gave encouraging results but better classification was achieved using the PLS regression.

\section{Other methods}

Lenhardt et al. (2014) classified samples of honey according to their botanical origin using synchronous front-face fluorescence spectroscopy combined with chemometrics. They used a total of 109 samples including three single-flower honeys (linden, acacia, and sunflower), mixed honey (mixture of meadow flowers) and adulterated honey (fake acacia and linden honey). Synchronous fluorescence spectrum was obtained by excitation between $240 \mathrm{~nm}$ and $500 \mathrm{~nm}$. Chemometric analysis was performed on the data obtained, and results show that the synchronous fluorescence spectra of different honey samples vary considerably due to their different physical and chemical properties, and provide sufficient data to clearly distinguish groups of honey. The spectra of adulterated honey samples are significantly different from the spectra of pure honey, allowing easy identification of adulterated honey. Based on the results of the study we can say that the method of front- 
face synchronous fluorescence spectroscopy is a valuable and promising method for the verification of botanical origin.

Sous a et al. (2014) studied the objectification of sensory perceptions. They found that it is possible to correctly classify single-origin honey as well as honey with high variability in botanical origin using an electronic language after pre-selection using honey colour: white, orange and deep-honey colour. Pollen analysis was performed as a comparison. The results showed that the device has satisfactory sensitivity with respect to the botanical origin of honey (Castanea spp., Echium spp., Erica spp., Lavandula spp., Prunus spp., and Rubus spp.). Cross-verification showed a classification accuracy of $100 \%$. Based on the study it can be concluded that this E-language has the potential for use in analytical laboratories for classification of honey samples according to quality indicators as a practical tool for ensuring the authenticity of single-flower honey.

\section{Entomological origin}

Honey is defined in national legislation (Decree of the Ministry of Agriculture no. 76/2003 Coll.) and supranational legislation (Council Regulation (EC) no. 797/2004 and Commission Regulation (EC) no. 917/2004) as the product of the bee species Apis mellifera. But there are many other species of bees, which also produce "honey", but according to the above legislation they cannot be considered true honey. Therefore, it is important to identify the bee species of bees which the sample of "honey" comes from.

Souza et al. (2006) analysed 152 samples of honey from bees without stings (Meliponini) in order to propose a standard for the quality of this product. Honey from Meliponini bees has a different composition than honey from Apis mellifera bees - some physico-chemical properties are altered. The entomological origin of honey was known for 17 kinds of bees from Brazil, one from Costa Rica, six from Mexico, 27 from Panama, one from Surinam, two from Trinidad and Tobago, and 7 from Venezuela - mostly belonging to the genus Melipona. Results indicate moisture (19.9 to $41.9 \mathrm{~g} / 100 \mathrm{~g}), \mathrm{pH}(3.15$ to 4.66), free fatty acids $(5.9-109 \mathrm{meq} / \mathrm{kg})$, ash $(0.01$ to $1.18 \mathrm{~g} / 100 \mathrm{~g})$, amylase activity $(0.9-23 \mathrm{DN})$, electric conductivity $(0.49$ to $8.77 \mathrm{mS} / \mathrm{cm}), \mathrm{HMF}(0.4$ to $78.4 \mathrm{mg} / \mathrm{kg})$, invertase activity (19.8-90.1 IU), nitrogen (14.34 to $144.00 \mathrm{mg} / 100 \mathrm{~g})$, reducing sugars $(58.0$ to $75.7 \mathrm{~g} / 100 \mathrm{~g})$ and sucrose $(1.1$ to $4.8 \mathrm{~g} / 100 \mathrm{~g})$. The content of moisture in the honey from Meliponini bees is generally higher than the maximum of $20 \%$ approved for A. mellifera honey. From the above study it is clear that continuous quality control of honey needs to be focused on both the beekeeper of Meliponini bees and on the harmonization of analytical methods for honey originating from these bees.

Silva et al. (2013) examined honey samples originating from Melipona (Michmelia) seminigra merrillae bees from seven different regions in Brazil. They analysed their botanical origin, the content and profile of phenolic compounds, antioxidant and antimicrobial activity and also performed pollen analysis. A total of 22 types of pollen were identified. Clidemia is the predominant type of pollen in honey from Melipona seminigra merrillae bees from Brazil. The total content of phenolic compounds ranged from 17 to $66 \mathrm{mg}$ GAE (gallic acid equivalents)/g extract. The highest values were found in honey containing Clidemia and Myrcia pollen. Honey from M. seminigra merrillae bees shows significant antioxidant and antimicrobial activity, with higher antioxidant activity observed in samples containing greater amounts of phenolic compounds. A total of 14 phenolic compounds were determined and Taxifolin was identified; this flavonoid has not been described in honey from the Melipona bees. Catechol compounds were identified for the first time in Brazilian honey.

\section{Detection of adulteration by overheating}

Long overheating of honey to temperatures above $50{ }^{\circ} \mathrm{C}$ destroys valuable substances in honey and this loss has a negative impact on the quality of honey. Overheated honey 
loses its biological value and significantly reduces the amount of vitamins and enzymes. In addition, overheating honey during processing can lead to the accumulation of elevated concentrations of hydroxymethyl furfural (HMF).

\section{Hydroxymethyl furfural (HMF)}

Hydroxymethyl furfural is an endogenous foreign substance. It is a highly reactive compound which can further react, e.g. undergo the Maillard reaction. It can thus reduce the nutritional value of honey through degradation of labile components. At higher concentrations it can influence the colour of honey. The opinion concerning the terms of health risks and potential cytotoxic, genotoxic, and carcinogenic effects of HMF is not consistent. The conditions in honey are favourable for the formation of HMF. The HMF content increases at elevated temperatures during storage. Hydroxymethyl furfural is also a good indicator of adulteration of honey by the addition of invert sugar. A value of $200 \mathrm{mg} /$ $\mathrm{kg}$ is considered as suspected adulteration of honey by invert sugar from acid hydrolysis, while a value of $500 \mathrm{mg} / \mathrm{kg}$ is considered conclusive evidence of the presence of invertsugar from acid hydrolysis (Kalábová et al. 2003). Hydroxymethyl furfural is routinely determined using HPLC.

Hošt'álková et al. (2013) analysed HMF in 17 honey samples of different botanical origin from 12 countries. The recently developed method of high-performance thin-layer chromatography (HPTLC) was limited by increased matrix effects during honey-sample application. The method was therefore modified to achieve higher sensitivity and to avoid matrix interference by using a rectangular application combined with focusing. The results of HPTLC were compared with results from the new spectrophotometric reflectoquant HMF assay. Both methods had quantification limits of $4 \mathrm{mg} / \mathrm{kg}$ which allowed for rapid quantification of HMF in honey with a strictly regulated concentration of $15 \mathrm{mg} / \mathrm{kg}$. The results showed that all 17 samples of honey were comparable with a standard deviation of $2.9 \mathrm{mg} / \mathrm{kg}(15 \%)$. The optimized HPTLC method has proven to be very robust.

For quantitative analysis of 5-hydroxymethyl furfural (5-HMF), Rajchl et al. (2013) tested the new direct analysis in real time (DART) technique with a broad potential for rapid screening when combined with high resolution time-of-flight mass spectrometry (TOF-MS). The DART/TOF-MS was optimized and validated. Quantification of 5-HMF was achieved by using a stable isotope labelled 5-HMF standard prepared from glucose. A total of 44 samples of honey, caramel, and sweetened condensed milk were analysed along with 50 model samples of heated honey. This confirmed the suitability of DART for analysis of heated honey. Also HPLC and DART/TOF-MS were compared as methods for determination of 5-HMF. It was demonstrated that DART/TOF-MS analysis is suitable for efficient and rapid determination of 5-HMF in various food substances such as honey and caramel.

Visquert et al. (2014) investigated the effect of temperature $\left(25,30,35\right.$, and $\left.40{ }^{\circ} \mathrm{C}\right)$ and storage time (62 and 104 days) on the colour, HMF content and diastase index (ID) of honey from citruses, rosemary, eucalyptus, honeydew, and mixed-origin honey. Samples were analysed according to the methods recommended by the European Commission for honey (Bogdanov et al. 1997). A lightening of the hue and a decrease in colour density was observed with increasing temperature and storage time. The decreases varied in extent depending on the botanical origin of the honey. Citrus honey showed the highest values of these indicators at all temperatures throughout the storage period. Honeydew honey showed the lowest value and the smallest colour differences. The values of HMF in honey were all low $(<10 \mathrm{mg} / \mathrm{kg})$, which was expected as the measurements were carried out immediately after harvest. The type of honey had a much greater influence on the content of HMF, ID, and colour than the storage conditions. Post-harvest treatment did not affect the characteristic colour of any type of honey. 
Enzymes (diastase, invertase)

Enzymes in honey are an important indicator for quality control. Invertase or diastase activities are used as indicators of heat damage to honey. Limits for the enzymatic activity of diastase are determined by national and EU legislation.

Lichtenberg-Kraag (2014) analysed amylase and invertase in honey. Enzymatic activity is an indicator reflecting the process of converting nectar into honey during the ripening process. Enormous differences in enzyme activity were demonstrated depending on the botanical origin, even though the enzymes are usually added by the bees. Therefore, samples of honey and nectar were collected during the honey maturation process and the activity of enzymes was studied keeping in mind the floral sources. The analysis of nectar samples demonstrates that floral source and environmental conditions influence the total content of sugars and sucrose concentration. Therefore, we hypothesized that nectar composition, especially the amount of sucrose, can integrate with invertase activity. The author found that the correlation between the concentration of sucrose and invertase activity is highly significant in the process of honey ripening $(P<0.0001)$. This effect was further illustrated using a sugar feeding experiment with defined concentrations of sucrose.

Sak-Bosnar and Sakač (2012) developed a new method for determining amylase activity. The method is based on direct potentiometric measurement of the tri-iodide ion, which is released upon the hydrosysis of a starch-tri-iodide complex. They found that increasing the concentration of tri-iodide ions in the sample is directly proportional to the diastase activity. They proposed a platinum redox electrode reaction mechanism which allows the calculation of the diastase activity factor $(\mathrm{F})$. The $\mathrm{F}$ values obtained by direct potentiometric method were compared with those obtained using the standard Phadebas method (DN values) and it was found that these two values are the same within experimental error. Finally, the amylase activity in 9 types of honey was successfully determined using the new methods developed here.

\section{Fermentation}

Fermentation occurs frequently when honey is harvested prematurely and this negatively affects the quality, because the water content is higher. Aged honey should contain about $19 \%$ water, and honey with higher water content is susceptible to fermentation. High humidity during storage or processing can dilute the upper layer of honey, making it more susceptible to fermentation. Higher storage temperature also entails a greater risk of fermentation. Fermentation can be detected by determining titratable acidity.

Comi et al. (2000) investigated whether indicators such as water activity, moisture, storage temperature, and yeast concentration may affect the fermentation of honey. The study concluded that a water activity of less than 0.57 , humidity lower than $18 \%$, storage temperature lower than $10{ }^{\circ} \mathrm{C}$, and yeast concentration lower than $100 \mathrm{UFC} / \mathrm{g}$ can inhibit yeast growth in the honey.

Schneider et al. (2003) analysed four fermented honeys of different geographical and botanical origins. They determined chemical, physical and microbiological properties - moisture content, water activity, electrical conductivity, $\mathrm{pH}$, free fatty acids, formalin content sugar spectrum, HMF content, glucose oxidase activity, and yeast counts. The botanical origin of honey was determined by pollen analysis. In all samples except for one with a high moisture content, the characterised chemical and physical properties allowed differentiation of standard quality honey. Yeast counts should not be used as a characteristic indicator for fermented honey. Remarkably, fermentation was observed even in honey samples with conditions seemingly unsuitable for microbial growth, such as low water activity and nitrogen content and a high anti-microbial activity. A total of twenty yeast strains were isolated from 4 honey samples. Identification was carried out using morphological 
and physiological indicators. All strains were identified as Zygosaccharomyces rouxii, or its imperfect form Candida mogii.

\section{Addition of sugars}

\section{Adulteration with $\mathrm{C} 4$ sugars}

Adulteration with $\mathrm{C} 4$ sugars is done mainly using corn and cane sugar. The official method to distinguish corn and cane sugar added to honey is the determination of the ${ }^{13} \mathrm{C} /{ }^{12} \mathrm{C}$ carbon isotope ratio. It uses the so-called SCIRI (stable carbon isotope ratio analysis). The calculation is done according to the equation ${ }^{13} \mathrm{C} /{ }^{12} \mathrm{C}=\mathrm{d}^{13} \mathrm{C}(\%)$. The method is expensive, requires considerable analytical skills and is not suitable for monitoring. The method compares the ratio of carbon isotopes in honey and the ratio of carbon isotopes in proteins separated from honey. This method is based on the fact that this ratio varies in plants depending on the type of photosynthesis. Sugar from cane and corn is derived from a metabolic pathway typical for C4 plants (Hatch-Slack cycle). Plants that are a source of nectar for honey have a different metabolic pathway typical for $\mathrm{C} 3$ plants (Calvin cycle). Both these pathways occur only in pears and cacti. Bees in principle prefer nectar from plants with the $\mathrm{C} 3$ cycle, i.e. C3 sugars. They may occasionally visit $\mathrm{C} 4$ plants. The average for pure honey is $-25.4(\%)$. As an internal standard, $\mathrm{d}^{13} \mathrm{C}$ of the proteins in honey is used; the difference between honey $\mathrm{d}^{13} \mathrm{C}$ and protein $\mathrm{d}^{13} \mathrm{C}$ should exceed $1(\%)$ and should be within the range of $+1.1(\%)$ to $-0.9(\%)$ in pure honey. This calculation can be used to determine the percentage of adulteration.

This method detects sugar addition exceeding 7\% (up to 10\%). It is not suitable for adulteration using beet syrup since the added sucrose is decomposed to under $5 \%$ due to the enzymes present. Isotope analysis, however, cannot reveal the feeding of colonies with $\mathrm{C} 3$ sugars such as beet, rice, and wheat sugars.

Souza-Kruliski et al. (2010) evaluated honey samples to detect adulteration. Samples were subjected to isotope analysis. Isotope values for honey carbohydrate were compared with the isotope values of honey proteins (internal standard). Samples where the difference between the isotopic values of protein and carbohydrates were equal to or lower than $-1 \%$ corresponded to contents of $7 \%$ of products originating in C4 plants. Samples considered adulterated were submitted to qualitative chemical analyses but were in some cases unable to reveal any adulteration. Among the 61 samples analysed, $18 \%$ were defective. Unlike the determination of chemical properties, isotope analysis proved to be effective for the identification and quantification of adulteration in commercial honey.

Cotte et al. (2007) analysed honey samples using stable carbon isotopic ratio analysis by mass spectrometry (SCIRA-MS). Isotopic fractions were measured using nuclear magnetic resonance (SNIF-NMR). The potential of these methods to characterise substances was initially verified and subsequently they were used to detect adulteration. Formal methods for the detection of added C4 syrups (AOAC 998.12 2005) revealed discrepancies in the pure samples resulting from the SCIRI indices that were lower than $-1 \%$. Filtration was included in the experimental procedure, and mixing with $\mathrm{C} 4$ syrups could be detected from $9-10 \%$. The detection limit for detecting syrup by SNIF-NMR is $20 \%$ which is insufficient.

Kropf et al. (2010) determined the isotopic properties $\left(\delta^{13} \mathrm{C}\right.$ honey, protein $\delta^{13} \mathrm{C}$ and $\delta^{15} \mathrm{~N}$ ) in 271 honey samples from four geographical regions in Slovenia. The stable isotope ratios of carbon and nitrogen were measured to examine the applicability of this method for the identification of the botanical and geographical origin of honey and adulteration. Six out of the 271 samples analysed $(2.2 \%)$ showed differences between the $\delta^{13} \mathrm{C}$ value of honey and $\delta^{13} \mathrm{C}$ value of the protein fraction of $>1 \%$, which indicates adulteration. Sucrose content was measured in these samples and the results revealed that the sugar added was not sucrose, but some other carbohydrate derived from $\mathrm{C} 4$ plants. 


\section{Adulteration with corn syrup}

High fructose corn syrup (HFCS) is formed by hydrolysis and isomerization of corn starch. Hydrolysis may be enzymatic or acidic, with the enzymatic route being more frequently employed. Based on their fructose content, these syrups are classified as: HFCS-42 (42\% fructose), HFCS-55 (55\% fructose), HFCS-90 (90\% fructose).

These syrups are used mainly for economic reasons as sugar substitutes in food production, particularly in soft drinks. For their low price and similar composition to honey, they are used to adulterate honey, although they are known to have a detrimental effect on the colony ( $\mathrm{pH}$ and HMF content) and the quality of the resulting honey. The HFCS is also used to feed bees, especially in winter and early spring. Determination of oligosaccharides that do not normally occur in honey is possible by capillary GC.

Megherbi et al. (2009) proposed an effective and simple analytical method for detecting corn syrup adulteration, the analysis of polysaccharide profiles. Monosaccharides and oligosaccharides were first removed, and chromatographic separation was performed using high performance anion exchange chromatography with pulsed amperometric detection. The polysaccharide fingerprint (degree of polymerization of 11 to 17) can then be used to detect the intentional addition of $1 \%$ corn syrup.

Agila and Barringer (2013) simulated honey adulteration by adding high fructose corn syrup (HFCS) at a concentration of $5 \%$ to $40 \%$, and the honey was stored at $37{ }^{\circ} \mathrm{C}$. The composition was measured by mass spectrometry (SIFT-MS). The concentration of most volatile compounds decreased with increasing HFCS concentration and storage duration. Soft independent modelling by class analogy (SIMCA) was used to distinguish volatile profiles of fresh and stored adulterated honey. Volatile profiles of intact honey and honey adulterated with $40 \%$ HFCS were significantly different. Honey adulteration and storage reduces the concentration of volatile compounds, and SIMCA was able to distinguish adulteration after storage.

Li et al. (2012) used Raman spectroscopy to detect impurities such as HFCS, and maltose syrup (MS) in honey. The HFCS and MS were each mixed into intact honey samples $(10 \%$, $20 \%$, and $40 \%$ ). The least squares method with linear discriminant analysis (PLS-LDA) was used to create a binary classification model. Classification authenticity of honey by PLS-LDA showed an overall accuracy of $91.1 \%$ (intact honey compared to honey mixture with HFCS), 97.8\% (intact honey compared to honey mixture with MS) and $75.6 \%$ (intact honey compared to honey mixture with HFCS and MS). Classification of blended honey by PLS-LDA results in an overall accuracy of $84.4 \%$. Results showed that Raman spectroscopy in combination with a PLS-LDA is suitable for the detection of potential HFCS and MS impurities in honey.

Ruiz-Matute et al. (2007) determined the carbohydrate composition of 20 samples of honey and 6 syrups [high fructose corn syrup (HFCS) and invert syrup (IS)] using gas chromatography (GC) and gas chromatography coupled with mass spectrometry (GC-MS) to detect differences between the two groups of samples. The presence of difructose anhydride (DFAS) in these syrups was described for the first time, with its content being dependent on the type of syrup. Since this compound was not detected in any of the 20 honey samples analysed, their presence in honey was proposed as a marker for detecting adulteration. Detection of adulteration of honey with HFCS and IS requires removal of the main sugars (monosaccharides) and subsequent determination of the DFAS concentration. The newly developed protocol enables the detection of DFAS in adulterated honey at low concentrations.

Sivakesava and Irudayaraj (2001) used a combination of infrared Fourier transform spectroscopy and multivariate procedures to determine the concentration of added sugar in honey. The spectra from the infrared region of honey adulterated with varying amounts of glucose, fructose, sucrose, and corn syrup were recorded. Results showed that infrared 
Fourier transform spectroscopy is a promising method of detecting honey adulteration using corn syrup within 5 min.

Morales et al. (2008) studied the profiles of oligosaccharides for detecting adulteration of honey using corn syrup (CS) and corn syrups high in fructose (HFCS). High molecular weight oligosaccharides (DP3-DP16) from 9 syrups and 25 honey samples were analysed by high performance anion exchange chromatography with pulsed amperometric detection (HPAEC-PAD). The samples were first exposed to the activated carbon for the removal of mono- and disaccharides. This method detects adulteration to $5 \% \mathrm{CS}$. Adulteration with HFCS was also successfully detected with varying degrees of isomerization $(20 \%$ and $40 \%)$.

\section{Adulteration with cane sugar}

Kerkvliet and Meijer (2000) analysed 17 samples of honey and 6 samples of cane sugar to study the suitability of microscopic analysis to detect adulteration with cane sugar. Microscopic analysis of samples was performed quantitatively by counting parenchymal cells, round cells and epidermal stem cells from sugarcane in a $10 \mathrm{~g}$ sample using polarized light microscopy. Repeatability of microscopic analysis was determined by calculating the standard deviation of 8 aliquots from the samples of honey. For all honey samples in this study, it was found that when the number of parenchymatous cells was more than 150 or the number of circular cells more than 10 in $10 \mathrm{~g}$, the samples were adulterated with sugars derived from $\mathrm{C} 4$ plants (sugarcane or maize). Microscopic techniques were able to detect suspicious honey adulterated to concentrations below 7\%. Overall, the microscopic procedure is a good screening method for detecting adulteration.

Paradkar and Irudayaraj (2002) used Fourier transform Raman spectroscopy to detect added cane and beet sugar in honey. Adulterated samples were characterized by FT- Raman in the region between 200 and 1600/cm and the fraction was used for quantitative and discriminant analysis. The results show that FT-Raman spectroscopy was effective in predicting invert mixes of cane and beet sugar in all three types of honey. Classification of impurities in honey by CVA gave a minimum accuracy of $96 \%$.

Zakaria et al. (2011) investigated the use of electronic nose (e-nose) and electronic tongue (e-tongue) in the adulteration of honey. They classified 18 samples of honey, syrups, and blends of honey and syrup. A total of 14 different brands of honey and two different kinds of syrup (cane sugar and beet sugar syrups) were obtained from commercial sources. Each group was evaluated separately by the e-nose and e-tongue. Using principal component analysis (PCA) and linear discriminant analysis (LDA) e-nose and e-tongue were able to independently distinguish single-origin honey, honey made from sugar syrup, multi-origin honey and mixtures of honey and sugar syrup.

\section{Adulteration with C3 sugars}

These include adulteration using rice, wheat, and beet syrups. The EA/LC-IRMS (a combination of isotope ratio mass spectrometry, elemental analysis, and liquid chromatography) is able to detect the addition of $\mathrm{C} 3$ sugars based on $\delta^{13} \mathrm{C}(\max$.) $\pm 2.1 \%$, in case isotopic values for fructose, glucose, and honey protein are unsatisfactory.

\section{Adulteration with rice syrup}

Most techniques cannot detect added rice syrup. The best available solution is LC-MS/MS which is very expensive. Adulteration with rice syrup with this method is based on the detection of 2-acetyl-3-glucopyranoside (AFGP) = indicator SM-R (specific marker - rice syrup), which does not occur in pure honey or the indicator TM-R (trace rice syrup) which can be demonstrated by ICP-MS based on the analysis of traces of arsenic.

Another possibility is to determine the exogenous gamma-amylases (glucoamylase, 
amyloglucosidase) using liquid chromatography coupled to isotope ratio mass spectrometry (LC-IRMS). The detection limit of this method is $10 \mathrm{U} / \mathrm{kg}$. The method is also useful in detecting invert sugar from corn and wheat.

Fei et al. (2012) tested LC-IRMS to determine the residual exogenous gamma-amylase enzyme in intact honey and honey with added rice syrup. Gamma-amylase is used for the cleavage of maltose into glucose. By measuring the glucose content using isotope ratio mass spectrometry, gamma-amylase can be detected in honey. The linear range of gamma-amylase activity was 5-200 U/kg with a detection limit of $5 \mathrm{U} / \mathrm{kg}$. This method was used to analyse 38 honey and rice syrup samples, and the detection rate of gamma-amylase was $76.3 \%$. To further verify the detection capability of this method honey was mixed with $15 \%$ rice syrup. The content of gamma-amylase in the sample was $10.2 \mathrm{U} / \mathrm{kg}$. This method can effectively identify adulteration of honey using rice syrup based on the principles of enzymology.

Zhao et al. (2013) detected adulteration of honey using rice syrup by three-dimensional fluorescence spectroscopy in combination with chemometric methods. This analysis combined linear discriminant analysis (LDA) with back propagation in an artificial neural network (BP-ANN). Results showed that the recognition rate of the LDA prediction model was $94.44 \%$, while the BP-ANN model may reach $100 \%$ if the number of major components is four. The results suggest that BP-ANN model is suitable for identifying adulteration. Three-dimensional fluorescence spectroscopy combined with BP-ANN model can be rapid, non-destructive and accurate in determining the adulteration of honey.

To detect adulteration with rice syrup Xue et al. (2013) developed a simple, fast and effective method of high performance liquid chromatography with diode array detection (HPLC-DAD). This method can detect adulteration based on 2-acetylfuran-3-glucopyranoside (AFGP), which is currently difficult to detect, as a characteristic compound present in rice syrup.

Cai et al. (2013) investigated the use of an electrochemical sensor along with chemometric methods for the analysis of honey samples adulterated with rice syrup. Cyclic voltammograms of the honey samples changed when the honey was mixed with rice syrup. A total of twelve variable functions were obtained from the electrochemical signals in cyclic voltammetry. Principal component analysis and linear discriminant analysis (PCA-LDA) has shown excellent performance in the identification of intact honey and adulterated honey. Overall results show that the electrochemical sensor in combination with chemometrics has significant potential in identifying adulteration.

\section{Adulteration with beet sugar}

Adulteration using beet sugar cannot be detected either by using the ratio of carbon isotopes $\left(\mathrm{C}^{13} / \mathrm{C}^{12}\right)$ of carbohydrates and proteins or by determining the profile of carbohydrates or sucrose concentrations. It is possible to determine and identify groups of unnatural (along with wheat) oligosaccharides (LC-ELSD) and also to demonstrate the presence of foreign enzymes, e.g. by determination of $\beta$-fructofuranosidase.

Beta-fructofuranosidase ( $\beta$-FF) is a foreign invertase (sucrase, $\alpha$-glucosidase) that breaks down sucrose into glucose and fructose (or invert, commercially used in foodstuffs). Determination is possible using HPLC-RID. The principle is the determination of the concentration of the product that arises from the cleavage of raffinose-melibiose. The detection limit of the method is $10 \mathrm{U} / \mathrm{kg}$. Determination of concentration $\beta-\mathrm{FF}$ is linear in the range of $10 \mathrm{U} / \mathrm{kg}$ to $200 \mathrm{U} / \mathrm{kg}$. Beta-FF at concentrations higher than $20 \mathrm{U} / \mathrm{kg}$ of honey is evidence of adulteration. The method is applicable also to detect cane sugar.

Cabańero et al. (2006) developed a new procedure for the determination of ${ }^{13} \mathrm{C}$ isotope ratios of individual sugars (sucrose, glucose, fructose) using a combination of liquid chromatography and isotope ratio mass spectrometry (HPLC-IRMS) for improved detection of adulteration. The $\delta^{13} \mathrm{C}$ values of honey were in the range of $-14.2 \%$ to 
$-27.2 \%$ and $\delta^{13} \mathrm{C}$ protein in the range $-23.6 \%$ to $-26.9 \%$. They observed a strong correlation between the ${ }^{13} \mathrm{C}$ ratios of sugars that are changed by adding sugar even at low concentrations. Using systematic differences $\Delta \delta^{13} \mathrm{C}$ [fruct-glu] $\Delta \delta^{13} \mathrm{C}$ [fruct-suc] $\Delta \delta^{13} \mathrm{C}$ [glu-suc] allows the detection of added sugars [C3-beet sugar; C4-cane-sugar cane syrup, isoglucose syrups and, high fructose corn syrup (HFCS)] with high accuracy. This new procedure has advantages over existing methods in terms of time and sensitivity. It was the first isotope method developed for detecting the amount of added beet sugar.

Li et al. (2013) investigated near-infrared spectroscopy (NIRS) combined with chemometric methods for qualitative and quantitative detection of beet syrup. The overall prediction accuracy of the test set was $90.2 \%$ for pure and adulterated honey samples. Quantitative analysis of the level of adulteration using PLS regression gave satisfactory results. Near-infrared spectroscopy can be used for rapid detection of adulterated honey samples, but not for detection of levels or quantification of adulteration with beet syrup.

Subari et al. (2012) compared infrared spectroscopy with Fourier transform with the electronic nose used to detect adulteration of honey. They used different concentrations of two types of sugar solutions (beet and cane sugar) and created honey samples containing $20 \%, 40 \%, 60 \%$, and $80 \%$ solutions. The data obtained from electronic nose and Fourier transform infrared spectroscopy (FTIR) were collected, analysed and compared on the basis of methods of nuclear synthesis. Fourier transform infrared spectroscopy identified $88.0 \%$ adulterated honey samples, suggesting that it was more accurate than the e-nose, which revealed tampering in $76.5 \%$ of the samples.

\section{Adulteration with $\mathrm{C} 3$ and $\mathrm{C} 4$ sugars}

To detect adulteration syrups $\mathrm{C} 3$ and $\mathrm{C} 4$ plants, $\mathrm{Fei}$ et al. (2011) used the isotopic method (LC/EA-IRMS). Based on the individual $\delta^{13} \mathrm{C}$ values found for the 38 pure samples of honey they proposed limits for honey. The $\delta^{13} \mathrm{C}$ difference between proteins and honey should be greater than or equal to $-0.95 \%, \delta^{13} \mathrm{C}$ difference between fructose and glucose should be from 0.53 to $-0.64 \%$, and maximum values $\delta^{13} \mathrm{C}$ difference between all components should be less than $2.09 \%$. The above criteria were verified on 58 samples with added sugar syrup from C4 or C3 plants and based on these LC/EA-IRMS was verified on 150 samples of commercial honey. Only 7 samples with added sugar syrup from $\mathrm{C} 4$ plants were detected by an official EA-IRMS method. The proposed method represents a significant improvement compared with the official EA-IRMS method.

Tosun (2013) studied the detection of adulteration of honey with high fructose corn syrup (HFCS), glucose syrup (GS), and sucrose syrup (SS) using isotope ratio mass spectrometry. Samples were prepared by adding HFCS, GS, and SS to honey at 0,10,20, 40, and 50\%. Adulteration using C4 syrup (HFCS and GS) could be detected to some extent, while adulteration of honey using $\mathrm{C} 3$ syrups (SS) could not be detected by this method.

Rios-Corripio et al. (2012) used attenuated total reflectance Fourier transform infrared spectroscopy (ATR-FTIR) and multivariate analysis for the analysis of honey adulterated by the addition of sugar solutions (glucose, fructose, and sucrose) and also inexpensive syrups (corn and sugarcane). Using principal component analysis (PCA) on pure and adulterated $(0-100 \%)$ honey samples determining the type of impurities was successfully carried out in a simple manner through the use of two- and three-dimensional PCA.

Sivakesava and Irudayaraj (2002) used an infrared Fourier transform spectroscopy as a screening tool for determining the type of sugar impurities in honey. The spectra of honey adulterated using simple and complex sugars were recorded in the mid-infrared region using attenuated total reflectance. Control sugars mixtures (glucose, fructose, and sucrose) and invert sugars (sucrose and invert beet sugar) were used. Classification of adulterated honey samples was carried out using discriminant analysis. The spectral data were compressed using principal component analysis and least squares method. Linear discriminant analysis 
was used to distinguish the type of impurities in three different types of honey. Optimal classification of $100 \%$ was achieved in honey samples adulterated with glucose, fructose, sucrose, beet, and cane invert sugar. Results showed that the discriminant analysis spectra of adulterated honey samples could be used for rapid detection of adulteration in honey.

Cordella et al. (2003) improved the method for the analysis and evaluation of the quality of honey. They proposed the determination of high performance chromatography profiles of sugars with anion exchange. When using this method both main and secondary sugars are analysed simultaneously. The technique is integrated in the new chemometric approach using chromatographic profiles of sugars for the characterization of honey in each sample analysed. Honey was obtained from French beekeepers in the years 2000 and 2001, and syrup samples from French industrial suppliers (Dorsman S.A.R.L; Ickovich SA). Samples were analysed by high performance anion exchange chromatography with pulsed amperometric detection. Parallel application of principal components analysis (PCA), linear discriminant analysis (LDA) and artificial neural networks (ANN) having a high efficiency of classification of the analysed samples (LDA 93\%, NS 100\%) and very good discrimination of different types of honey. This work is the basis for the development of a new system designed for automatic detection of food samples (to be applied first on honey) using chromatographic analysis for the characterization and detection of food adulteration.

Cordella et al. (2002) used differential scanning calorimetry (DSC) to study the thermal behaviour of pure honey and industrial sugar syrups obtained from French industrial suppliers (Dorsman SARL, Ickovich SA). They investigated the effect of different amounts of syrup adulteration $(5,10,20,40$, and $60 \%)$ on thermal and thermochemical properties such as glass transition temperature ( $\mathrm{Tg})$, melting enthalpy ( $\Delta \mathrm{Hfus})$, and the change in heat capacity $(\Delta \mathrm{Cp})$. Syrups and honey showed significant differences in the thermal phenomena, as well as their amplitudes and positions on the temperature scale. The results demonstrated good reproducibility of the method for all studied samples. They found a linear relationship between the percentage of the added syrup and the glass transition temperature. A similar relation was obtained from results of melting enthalpy for temperatures from 40 to $90{ }^{\circ} \mathrm{C}$. Under these conditions, it seems possible to detect adulteration of honey using industrial syrups up to a concentration of $5 \%$.

\section{Adulteration with individual sugars}

Wang et al. (2010) used Fourier transform infrared spectroscopy (FTIR) in combination with chemometrics for the determination of glucose, fructose, sucrose, and maltose in honey. The calibration series consisted of 45 standard mixtures of known concentrations of sugar, composed of sucrose $(0.20 \%$ to $5.45 \%)$, glucose ( $4 \%$ to $15.26 \%)$, fructose $(4.99 \%$ to $14.09 \%)$, and maltose $(0.22 \%$ to $6.76 \%)$. All mixtures of sugar had a spectral "fingerprint" in the region between 1500 and $800 / \mathrm{cm}$. Calibration of the model was successfully validated using seven sets of synthetic sugar mixtures. The model was confirmed by high performance liquid chromatography on commercial samples of honey. The study showed that the FTIR method can be used to detect honey adulteration. This method can be used to quantitatively and qualitatively determine glucose, fructose, sucrose, and maltose in honey samples. Kelly et al. (2004) also used FTIR with attenuated total reflection (ATR) to detect adulteration. The sample included 320 spectra, 99 from pure honey and 221 from adulterated honey. Solutions containing fructose and glucose in the following ratios: 0.7: 1.0, 1.2: 1.0 (typical composition of honey), and 2.3: 1.0 were used as admixtures. Each mixture was added to each sample of honey at $7 \%, 14 \%$, and $21 \%$. The spectral data were compressed and analysed using the $\mathrm{K}$-nearest neighbours (KNN) and partial least squares (PLS) regression techniques. The best classification was achieved with a PLS regression with an overall classification rate of $93 \%$. This model correctly identified $99 \%$ of the samples adulterated at $14 \%$ and higher. This method is a rapid screening technique for the detection of this type of adulteration. 
Zhu et al. (2010) used near-infrared spectroscopy (NIR) in combination with chemometric methods to detect adulteration of honey samples. The collection contained 135 spectra of 68 pure honey samples and 67 samples of honey with an added mixture of glucose and fructose at the ratios of 0.7:1, 1.2: 1 , and 2.3: 1 . Spectral data were compressed using a wavelength transform and principal component analysis (PCA). A total of five methods of classification modelling were used - least squares support vector machine (LS-SVM), support vector machine (SVM), back propagation artificial neural network (BP-ANN), linear discriminant analysis (LDA) and K-nearest neighbours (KNN). Wavelength transform (WT) proved more effective than PCA as a means for selecting the variables. The best classification model was achieved with LS-SVM. Results showed that WT-LS-SVM can be used as a rapid screening technique for detecting adulteration with good accuracy.

To identify intact and adulterated honey $\mathrm{Ou}$ et al. (2011) used ultraviolet-visible spectroscopy (UV-VIS) in combination with chemometrics. Fructose and glucose at a ratio typical for the composition of honey was added to each honey sample at concentrations of $5,10,15$, and $20 \%$. Absorption spectra of intact and adulterated honey were obtained in the wavelength range $220-750 \mathrm{~nm}$. The absorbance $(250-400 \mathrm{~nm})$ values were selected to create the models. An optimal identification model was developed using principal components analysis combined with back propagation of an artificial neural network (PCA-BP-ANN). Optimal principal components values were used as the input vectors of the model. The results showed that UV-VIS spectroscopy based on PCA-BP-ANN can be used as a convenient, fast, and accurate method for identification of pure and adulterated honey.

Puscas et al. (2013) developed and validated a method based on high performance thin layer chromatography (HPTLC) in combination with image analysis for detecting honey adulterated using solutions of glucose, fructose, and sucrose. The optimal mobile phase was ethyl acetate-pyridine-water-acetic acid at a ratio of 6:3:1:0.5. Glucose, fructose, and sucrose were separated on silica gel HPTLC plates. Documentation of the plates was performed using TLC visualization device and the plate images were processed using a digital processor. High performance thin layer chromatography was tested for selectivity, linearity and range, precision, and robustness. The method was successfully applied for the quantitative determination of glucose, fructose and sucrose.

Guo et al. (2011) found that pure honey had a higher dielectric constant than pure sugar syrup. Dielectric properties can be used to detect adulteration. Adulteration by adding fructose is common in acacia honey which is naturally less sweet. High performance thin layer chromatography can detect this adulteration based on the ratio of fructose/glucose (normal 1-1.2).

Ruiz-Matute et al. (2010b) looked for a marker for detecting adulteration of honey using high fructose inulin syrups (HFIS) using gas chromatography coupled with mass spectrometry (GC-MS). They first studied the composition of saccharides in HFIS with different degrees of polymerization (fructose, sucrose, fructose dianhydrides, inulobiose, kestose, and inulotriose) and the carbohydrate composition of honey samples. Then they blended honey with $5 \%, 10 \%$, and $20 \%$ HFIS. Inulotriose proved to be the best marker for detecting adulteration with these syrups because they were not detected in any of the analysed samples of pure honey.

\section{Adulteration using sulphite-ammonia caramel}

Dark honey is usually referred to as "forest honey" and quite often the dye sulphite ammonia caramel (E150d) is added. This is mainly due to the higher sale price of dark honey. Determination of the content of ammonia sulphite caramel is possible with liquid chromatography tandem mass spectrometry (LC-MS/MS). A level of caramel E150d above the limit of quantification methods $(>5 \mathrm{mg} / \mathrm{kg}$ ) is considered an infringement of regulations (Bartošová 2013). 
In conclusion, a large number of methods focus on the determination of a limited number of indicators, which is insufficient to detect the current methods of honey adulteration. It is no longer possible to focus on one indicator only, but a wide range of quality indicators need to be determined in order to detect honey adulteration, while monitoring a combination of such indicators and, in response to new data, revising existing legislation. It is also necessary to develop new methods and standards capable of detecting the presence and level of indirect adulteration of honey.

\section{Acknowledgments}

This study was supported by the Internal Grant Agency of the University of Veterinary and Pharmaceutical Sciences (Project No. 72/2010/FVHE).

\section{References}

Abdel - Aal ESM, Zeina HM, Youssef MM 1993: Aduleration of honey with high fructose corn syrup - Detection by different methods. Food Chem 48: $209-212$

Acquarone C, Buera P, Elizalde B 2007: Pattern of pH and electrical conductivity upon honey dilution as a complementary tool for discriminating geographical origin of honeys. Food Chem 101: 695-703

Agila A, Barringer S 2013: Effect of adulteration versus storage on volatiles in unifloral honeys from different floral sources and locations. J Food Sci 78: 184-191

Almeida-Muradiana LB, Sousa RJ, Barth OM, Gallmann P 2014: Preliminary data on Brazilian monofloral honey from the northeast region using FT-IR ATR spectroscopic, palynological, and color analysis. Química Nova 37: $716-719$

Anklam EA 1998: Review of the analytical methods to determine the geographical and botanical origin of honey. Food Chem 63: 549-562

AOAC 1995: Official Method of Analysis, 978.17, Corn and cane sugar products in honey. Association of Official Analytical Chemists, Arlington, VA, USA, chapter 44: 27-29

AOAC 1995: Official Method of Analysis, 991.41, C4 plant sugars in honey. Association of Official Analytical Chemists, Official Methods of Analysis Sugars and Sugar Products, Arlington, VA, USA, chapter 44: 29-31

AOAC 2005: Official Method of Analysis, 998.12, C4 plant sugars in honey. International standard stable carbon isotope ratio method. Int. Gaithersburg, MD, USA, chapter 44: 27-30

Bartošová L 2013: Methods for proving adulteration (in Czech). SZPI. Available at: http://www.szpi.gov. cz/docDetail.aspx?docid=1049475\&docType=ART\&nid=12075. Last modified May 24, 2013. Accessed September 7, 2014

Belay A, Solomon WK, Bultossa G, Adgaba N, Melaku S 2014: Botanical origin, colour, granulation, and sensory properties of the Harenna forest honey, Bale, Ethiopia. Food Chem 167: 213-219

Bertelli D, Lolli M, Papotti G, Bortolotti L, Serra G, Plessi M 2010: Detection of honey adulteration by sugar syrups using one-dimensional and two-dimensional high-resolution nuclear magnetic resonance. J Agric Food Chem 58: 8495-8501

Bogdanov S, Martin P, Lullmann C 1997: Harmonised methods of the European honey commission, Apidologie (extra issue), 1-59

Bogdanov S, Ruoff K, Oddo LP 2004: Physico-chemical methods for the characterisation of unifloral honeys: A review. Apidologie 35: 4-17

Cabańero AI, Recio JL, Rupérez M 2006: Liquid chromatography coupled to isotope ratio mass spectrometry: A new perspective on honey adulteration detection. J Agric Food Chem 54: 9719-9727

Cai J, Wu X, Yuan L, Han E, Zhoua L, Zhoub A 2013: Determination of Chinese angelica honey adulterated with rice syrup by an electrochemical sensor and chemometrics. Anal Meth 5: 2324-2328

Castro-Vázquez L, Leon-Ruiz V, Alañon ME, Pérez-Coello MS, González-Porto AV 2014: Floral origin markers for authenticating Lavandin honey (Lavandula angustifolia $x$ latifolia). Discrimination from Lavender honey (Lavandula latifolia). Food Control 37: 362-370

Cimpoiu C, Hosu A, Miclaus V, Puscas A 2013: Determination of the floral origin of some Romanian honeys on the basis of physical and biochemical properties. Spectr Acta Part A: Mol Biomol Spectr 100: 149-154

Codex Alimentarius - Revised Codex Standard for honey - 2001: Codex stan. 12-1981, Rev.1 (1987), Rev. 2 (2001), 7 p.

Comi G, Manzano M, Lenardon M, Cocolin L, Cantoni C 2000: Evaluation of the parameters ( $\mathrm{a}_{\mathrm{w}}$, humidity, storage temperature and osmophilic yeasts concentration) influencing yeast fermentation in honey. Industr Alim 39: 1127-1133

Cordella CH, Antinelli JFO, Aurieres C, Faucon JP, Cabrol-Bass D, Sbirrazzuoli N 2002: Use of differential scanning calorimetry (DSC) as a new technique for detection of adulteration in honeys. 1. study of adulteration effect on honey thermal behavior. J Agric Food Chem 50: 203-208

Cordella CHBY, Militão JSLT, Cleäment MC, Cabrol-Bass D 2003: Honey characterization and adulteration 
detection by pattern recognition applied on HPAEC-PAD profiles. 1. honey floral species characterization. J Agric Food Chem 51: 3234-3242

Cordella CH, Militão JSLT, Clément MC, Drajnudel P, Cabrol-Bass D 2005: Detection and quantification of honey adulteration via direkt incorporation of sugar syrups or bee-feeding: preliminary study using highperformance anion exchange chromatography with pulsed amperometric detection (HPAEC-PAD) and chemometrics. Anal Chim Acta 531: 239-248

Cotte JF, Casabianca H, Lhéritier J, Perrucchietti C, Sanglar C, Waton H, Grenier-Loustalot MF 2007: Study and validity of ${ }^{13} \mathrm{C}$ stable carbon isotopic ratio analysis by mass spectrometry and ${ }^{2} \mathrm{H}$ site-specific natural isotopic fractionation by nuclear magnetic resonance isotopic measurements to characterize and control the authenticity of honey. Anal Chim Acta 582: 125-136

Cozzolino D, Corbella E, Smyth HE 2011: Quality control of honey using infrared spectroscopy: A review. Appl Spectr Rev 46: 523-538

European Union (EU): Council Directive 2001/110/EC of 20 December 2001 relating to honey. OJL 32001L0110

European Union (EU): Council Regulation (EC) No 797/2004 of 26 April 2004 on measures improving general conditions for the production and marketing of apiculture products. OJL 32004R0797

European Union (EU): Commission Regulation (EC) No 917/2004 of 29 April 2004 on detailed rules to implement Council Regulation (EC) No 797/2004 on measures improving general conditions for the production and marketing of apiculture products. OJL 32004R1484

Fei X, Wu B, Sehn C, Ding T, Li L, Lu Y 2011: Honey adulteration detection using liquid chromatography/ elemental analysis-isotope ratio mass spektrometry. Chinese J Chrom 29: 5-19

Fei X, Wu B, Shen C, Zhang R, Ding T, Li L 2012: Determination of exogenous gamma-amylase residue in honey. Chinese J Chrom 30: 777-781

Guertler P, Eicheldinger A, Muschler P, Goerlich O, Busch U 2014: Automated DNA extraction from pollen in honey. Food Chem 149: 302-306

Guler A, Kocaokutgen H, Garipoglu AV, Onder H, Ekinci D, Biyik S 2014: Detection of adulterated honey produced by honeybee (Apis mellifera L.) colonies fed with different levels of commercial industrial sugar (C3 and C4 plants) syrups by the carbon isotope ratio analysis. Food Chem 155: 155-160

Guo W, Liu Y, Zhu X, Wang S 2011: Dielectric properties of honey adulterated with sucrose syrup. J Food Eng 10: $1-7$

Hoštálková A, Klingelhöfer I, Morlock GE 2013: Comparison of an HPTLC method with the Reflectoquant assay for rapid determination of 5-hydroxymethylfurfural in honey. Anal Bioanal Chem 405: 9207-9218

Kalábová K, Vorlová L, Borkovcová I, Smutná M, Večerek V 2003: Hydroxymethylfurfural in Czech honeys. Czech J Animal Sci 48: 551-557

Kelly JFD, Downey G, Fouratier V 2004: Initial study of honey adulteration by sugar solutions using midinfrared (MIR) spectroscopy and chemometrics. J Agric Food Chem 52: 33-39

Kerkvliet JD, Meijer HAJ 2000: Adulteration of honey: relation between microscopic analysis and $\delta^{13} \mathrm{C}$ measurements. Apidologie 31: 717-726

Kropf U, Golob T, Emer MN, Kump P, Korošec M, Bertoncelj J, Ogrinc N 2010: Carbon and nitrogen natural stable isotopes in Slovene honey: Adulteration and botanical and geographical aspects. J Agric Food Chem 58: 12794-12803

Lenhardt L, Zekovic I, Dramicanin T, Dramicanin MD, Rasmus B 2014: Determination of the botanical origin of honey by front-face synchronous fluorescence spectroscopy. Appl Spectr 68: 557-563

Li S, Shan Y, Zhu X, Zhang X, Ling G 2012: Detection of honey adulteration by high fructose corn syrup and maltose syrup using Raman spectroscopy. J Food Compos Anal 28: 69-74

Li SF, Wen RZ, Yin Y, Zhou Z, Shan Y 2013: Qualitative and quantitative detection of beet syrup adulteration of honey by near-infrared spectroscopy: a feasibility study. Guang pu 33: 2637-2641

Lichtenberg-Kraag B 2014: Evidence for correlation between invertase activity and sucrose content during the ripening process of honey. J Apicul Res 53: 364-373

Ministry of Agriculture 2003: Czech Decree No. 76/2003 Coll., laying down the requirements for natural sweeteners, honey, sweets, cacao powder and cacao mixtures with sugar, chocolate, and chocolate candies

Megherbi M, Herbreteau B, Faure R, Salvador A 2009: Polysaccharides as a marker for detection of corn sugar syrup addition in honey. J Agric Food Chem 57: 2105-2111

Mehryar L, Esmaiili M 2011: Honey and honey adulteration detection: A Review. In proceeding of 11th International congress on engineering and food - Athens, Greece 3 (iCEF11)

Morales V, Corzo N, Sanz ML 2008: HPAEC-PAD oligosaccharide analysis to detect adulterations of honey with sugar strupe. Food Chem 107: 922-928

Ou WJ, Meng YY, Zhang XY, Kong M 2011: Application of UV visible absorption spectroscopy and principal components back propagation artifical neural network to identification of authentic and adulterated honeys. Chinese J Anal Chem 39: 1104-1108

Paradkar MM, Irudayaraj J 2002: Discrimination and classification of beet and cane inverts in honey by FTRaman spectroscopy. Food Chem 76: 231-239

Puscas A, Hosu A, Cimpoiu C 2013: Application of a newly developed and validated high-performance thin-layer chromatographic method to control honey adulteration. J Chrom A 1272: 132-135 
Puusepp L, Koff T 2014: Pollen analysis of honey from the Baltic region, Estonia. Grana 53: 54-61

Rajchl A, Drgová L, Grégrová A, Čížková H, Ševčík R, Oldřich M 2013: Rapid determination of 5-hydroxymethylfurfural by DART ionization with time-of-flight mass spektrometry. Anal Bioanal Chem 405: 4737-4745

Rios-Corripio MA, Rojas-López M, Delago-Macuil R 2012: Analysis of adulteration in honey with standard sugar solutions and syrups using attenuated total reflectance - Fourier transform infrared spectroscopy and multivariate methods. CyTA J Food 10: 119-122

Ruiz-Matute AI, Soria AC, Martínez-Castro I, Sanz ML 2007: A new methodology based on GC-MS to detect honey adulteration with commercial syrups. J Agric Food Chem 55: 7264-7269

Ruiz-Matute AI, Weiss M, Sammataro D, Finely J, Sanz ML 2010a: Carbohydrate composition of high-fructose corn syrups (HFCS) used for bee feeding: Effect on honey composition. J Agric Food Chem 58: 7317-7322

Ruiz-Matute AI, Rodríguez-Sánchez S, Sanz ML, Martínez-Castro I 2010b: Detection of adulterations of honey with high fructose syrups from inulin by GC analysis. J Food Compos Anal 23: 273-276

Sak-Bosnar M, Sakač N 2012: Direct potentiometric of diastase activity determination of diastase activity in honey. Food Chem 135: 827-831

Schneider A, Horn H, Hammes WP 2003: The occurrence of osmophilic yeasts in honey. Deutsche Lebensmittelrundschau 99: 310-319

Silva IAA, Silva TMS, Camara CA, Queiroz N, Magnani M, Novais JS, Soledade LEB, Lima EO, Souza AL, Souza AG 2013: Phenolic profile, antioxidant activity and palynological analysis of stingless bee honey from Amazonas, Northern Brazil. Food Chem 141: 3552-3558

Silvano MF, Varela MS, Palacio MA, Ruffinengo S, Yamul DK 2014: Physicochemical parameters and sensory properties of honeys from Buenos Aires region. Food Chem 152: 500-507

Sivakesava S, Irudayaraj J 2001: A rapid spectroscopic technique for determining honey adulteration with corn syrup. J Food Sci 66: 787-792

Sivakesava S, Irudayaraj J 2002: Classification of simple and complex sugar adulterants in honey by mid-infrared spectroscopy. Int J Food Sci Tech 37: 351-360

Sousa MEBC, LG Dias, Veloso ACA, Estevinho L, Peres AM, Machado AASC 2014: Practical procedure for discriminating monofloral honey with a broad pollen profile variability using an electronic tongue. Talanta 128: $284-292$

Souza B, Roubik D, Barth O, Heard T, Enríquez E, Carvalho C, Villas-Bôas J, Marchini L, Locatelli J, PersanoOddo L, Almeida-Muradian L, Bogdanov S, Vi P 2006: Composition of stingless bee honey: Setting quality standards. Interciencia 31: 867-875

Souza-Kruliski CR, Ducatti C, Filho VWG, Orsi RO, Silva ET 2010: A study of adulteration in brazilian honeys by carbon isotope ratio. Cięncia e Agrotecnologia 34: 434-439

Subari N, Saleh JM, Shakaff AYM, Zakaria A 2012: A hybrid sensing approach for pure and adulterated honey classification. Senzore 12: 14022-14040

Tosun M 2013: Detection of adulteration in honey samples added various sugar syrups with $13 \mathrm{C} / 12 \mathrm{C}$ isotope ratio analysis metod. Food Chem 138: 1629-1632

Visquert M, Vargas M, Escriche I 2014: Effect of postharvest storage conditions on the colour and freshness parameters of raw honey. Int J Food Sci Tech 49: 181-187

Wang J, Kliks MM, Jun S, Jackson M, Li QX 2010: Rapid analysis of glucose, fructose, sucrose, and maltose in honeys from different geographic regions using Fourier transform infrared spectroscopy and multivariate analysis. J Food Sci 75: 208-214

Woodcock T, Downey G, Kelly JD, O’Donnell C 2007: Geographical classification of honey samples by nearinfrared spectroscopy: A feasibility study. J Agri Food Chem 55: 9128-9134

Xue X, Wang Q, Li Y, Wu L, Chen L, Zhao J, Liu F 2013: 2-acetylfuran-3-glucopyranoside as a novel marker for the detection of honey adulterated with rice syrup. Agric Food Chem 61: 7488-7493

Zakaria A, Shakaff AYM, Masnan MJ, Ahmad MN, Adom AH, Jaafar MN, Ghani SA, Abdullah AH, Aziz AHA, Kamarudin LM, Subari N, Fikri NA 2011: A biomimetic sensor for the classification of honeys of different floral origin and the detection of adulteration. Senzore 11: 7799-7822

Zhao JW, Han XY, Chen QS, Ouyang Q 2013: Identification of adulterated honey based on three dimensional fluorescence spectra technology. Spectr Spectral Anal 33: 1626-1030

Zhu X, Li S, Shan Y, Zhang Z, Li G, Su D, Liu F 2010: Detection of adulterants such as sweeteners materials in honey using near -infrared spectroscopy and chemometrics. J Food Eng 101: 92-97 